\title{
Development, competence and performance - who does what in higher education?
}

\author{
Mariana NICOLAE \\ The Bucharest University of Economic Studies, Bucharest, Romania \\ mariana.nicolae@rei.ase.ro \\ Elena E. NICOLAE \\ The Bucharest University of Economic Studies, Bucharest, Romania
}

\begin{abstract}
Higher education is in turmoil in the whole world. Universities as organizations are being challenged by their various stakeholders. This is true of any and most organizations. Nevertheless in some places universities continue to be looked upon as providers of the correct answers to those challenges as they have rallied within their ranks self-proclaimed experts in leadership, management and organizational performance. The literature existing documents the issues universities as organizations face in today's complex world and attempts at pointing at various ways they can take to address those challenges. Specialists and sometimes the general public itself show an understanding of the fact that higher education evolves through its institutions, practices and processes at some paces in global contexts and at different ones in local contexts in spite of a relatively unifying public discourse used especially by decision and policy makers and some parts of the media. In other words, similar concepts may refer to very dissimilar realities making the evaluation of performance difficult and questionable. This paper looks at the way universities address the need for professional development of their leaders and/or managers at the various university levels. The focus will be on Romanian economic and business higher education institutions. The research presented here evolved from a doctoral study one the authors did in the field of leadership in Romanian higher education and from both authors' experience in the university system in Romania and in other higher education systems they are familiar with. The authors claim and document that in Romania little is still done in terms of formalized, transparent and open access training for university leaders and administrators. The same is true for those who are interested in preparing for a career in academic management or leadership and do not have a clear road map to follow. In the complex higher education system of today professional competence is an important component that cannot be left entirely to personal development needs. Formalized and open access training in management, leadership, educational management, research management, organizational culture, strategic planning and time management skills is critical for one's professional competence. In Romania both organizations and individuals need to understand the need to offer opportunities for professional training and the need to invest in personal development. This is how academics working or contemplating to work in administration would be empowered to plan for their organization's performance in an open, transparent, continually and unpredictably changing world.
\end{abstract}

Keywords: higher education, academic leadership, academic management, personal development, professional competence, university performance.

\section{Introduction}

The value of higher education and its merits for individuals and communities are under discussion everywhere in the world with more nuanced and definitely polarized positions than ever before. In an article in the Financial Times, Tim Hartford (2016), an Oxford graduate, looks at two main and opposite views on higher education: higher education is good and worth having and therefore needs more investment, on the one hand, and higher education is not offering anything of real value to graduates and 
consequently does not justify the continuously increasing number of universities, on the other.

Brian Caplan, a U.S. economics professor has long been pointing out (2012) not unreasonably - that many students seem to learn nothing of any obvious relevance to the workplace, things like Latin, history, higher mathematics, music, art, Shakespeare or foreign languages, but, on graduation, they are rewarded with much better career prospects than people who chose not to attend university. In other words, companies pay a large bonus to people who study subjects unrelated to their work. Caplan explains this situation by emphasizing that education is a signal for what is otherwise difficult to evaluate but is much valued and needed in the workplace. And he talks about character components and skills which most applicants claim to have, but are difficult and expensive to assess even in sophisticated assessment centres. Discipline, coping with challenges, meeting deadlines, working under pressure, being a good co-worker, being able to communicate, thinking critically and creatively, etc. are all delivered through university study programmes. This is how the author explains that the value of undergraduate degrees for society consists in streamlining graduates, in becoming a gatekeeper to higher salaries, and lies not therefore in their intrinsic worth, no matter what universities might otherwise claim. Caplan concludes that, possibly, the world might become better if it renounced creating more universities or heavily investing in the old ones.

What happens in Romania? Although we have plenty of problems both in our society and in our education system, this is not a problem we have at the present moment. For a long time, higher education has been perceived in Romania as a very desirable personal and social accolade. In spite of this idealistic position towards higher education, due to various social and economic constraints, Romania is still lagging behind the rest of the EU in terms of number of students compared to the rest of its population as can be observed in Figure 1.

Part of this issue is the lack of appropriate government investment in the education system which has slowly but clearly deteriorated to the present state (Nicolae, 2015; Nicolescu, 2010). Romanian decision-makers, no matter of their political affiliation, seem to be unaware that higher education evolves through individuals and only then through its institutions, practices and processes and needs both financial investments and societal support through a public discourse that stops incriminating and demonizing education and educators for almost all the failures of the postcommunist Romanian society (Seitz, Nicolae 2014). Public discourse in Romania is indeed well connected to and pays lip service to the latest international conversations around higher education; however the Romanian reality has another quality than the systems we are trying to emulate and our understanding of concepts discussed internationally is heavily indebted to our own context and history.

The international market of higher education has become highly competitive and this makes life difficult for universities in emerging economies, like Romania, mainly because such countries and their universities lose students and, occasionally, staff to the most developed markets. The globalization of education has increased the perceived competitiveness of European institutions of higher education compared with other parts of the world and as such of the member states of the European Union (EU). Even if Romania is among the last in the EU in terms of comparable indicators in many fields, it is still considered as a desirable study destination for lower income categories of people coming mainly from the Middle East or Asia Pacific. 


\begin{tabular}{|c|c|c|c|c|c|c|c|c|c|c|c|c|c|c|c|}
\hline & \multicolumn{3}{|c|}{ Tertiary total } & \multicolumn{3}{|c|}{ Short-cycle tertiary } & \multicolumn{3}{|c|}{ Bachelor's or equivalent } & \multicolumn{3}{|c|}{ Master's or equivalent } & \multicolumn{3}{|c|}{ Doctoral or equivalent } \\
\hline & Total & Male & Female & Total & Male & Female & Total & Male & Female & Total & Male & Female & Total & Male & Female \\
\hline EU-28(C) & 19632.3 & 8969.1 & 10663.2 & 1475.4 & 6882 & 7873 & 11913.5 & 5541.8 & 6371.6 & 5507.4 & 2344.6 & 31627 & 736.0 & 394.5 & 341.5 \\
\hline Belgium & 488.5 & 216.3 & 272.2 & 24.1 & 9.2 & 15.0 & 3642 & 160.2 & 2040 & 85.6 & 39.0 & 46.5 & 14.6 & 8.0 & 6.6 \\
\hline Bulgaria & 284.0 & 129.1 & 154.9 & - & - & - & 195.6 & 91.9 & 1038 & 830 & 34.6 & 48.4 & 5.4 & 2.6 & 2.7 \\
\hline Czech Republic & 427.4 & 182.0 & 245.4 & 1.0 & 0.4 & 0.6 & 267.7 & 115.3 & 1524 & 133.5 & 52.2 & 81.3 & 25.2 & 14.2 & 11.0 \\
\hline Denmark & 291.1 & 125.5 & 165.7 & 31.7 & 16.2 & 15.5 & 1823 & 75.3 & 107.0 & 67.5 & 29.1 & 38.4 & 9.6 & 4.8 & 4.8 \\
\hline Germany & 2780.0 & 1469.9 & 1310.1 & 0.5 & 0.1 & 0.4 & 1635.9 & 913.3 & 722.6 & 930.4 & 429.7 & 500.6 & 213.2 & 126.8 & 86.4 \\
\hline Estonia & 64.8 & 26.9 & 37.9 & - & - & - & 448 & 19.5 & 253 & 17.0 & 6.2 & 10.8 & 3.0 & 1.3 & 1.8 \\
\hline Ireland & 199.4 & 98.8 & 100.6 & 41.6 & 24.4 & 17.3 & 121.2 & 56.9 & 643 & 28.4 & 13.4 & 15.0 & 8.2 & 4.1 & 4.1 \\
\hline Greece & 659.3 & 337.7 & 321.6 & - & - & - & 588.2 & 305.4 & 2828 & 48.1 & 20.2 & 27.9 & 23.0 & 12.1 & 10.9 \\
\hline Spain & 1969.4 & 914.8 & 10546 & 346.4 & 174.5 & 171.9 & 1085.0 & 497.5 & 587.5 & 514.4 & 230.5 & 283.8 & 23.7 & 12.3 & 11.4 \\
\hline France & 2338.1 & 1062.6 & 1275.6 & 504.9 & 251.6 & 253.3 & 931.7 & 387.2 & 544.6 & 832.0 & 387.1 & 444.9 & 69.5 & 36.7 & 32.8 \\
\hline Croatia (") & 164.6 & 71.7 & 92.9 & & & & 102.8 & 48.2 & 54.6 & 58.2 & 21.9 & 36.3 & 3.6 & 1.7 & 20 \\
\hline Italy & 1872.7 & 804.1 & 1068.5 & 2.5 & 1.9 & 0.6 & 1108.3 & 497.2 & 611.1 & 727.0 & 288.1 & 438.9 & 34.9 & 16.9 & 18.0 \\
\hline Cyprus & 32.0 & 14.3 & 17.7 & 3.3 & 1.4 & 1.9 & 20.0 & 9.5 & 10.5 & 79 & 3.0 & 49 & 0.8 & 0.4 & 0.5 \\
\hline Latvia & 94.5 & 38.7 & 55.7 & 17.3 & 7.0 & 10.3 & 63.3 & 26.4 & 36.9 & 11.3 & 4.2 & 7.1 & 2.5 & 1.1 & 1.4 \\
\hline Lithuania & 159.7 & 66.4 & 93.2 & - & - & - & 1245 & 54.4 & 70.1 & 32.5 & 10.9 & 21.6 & 2.7 & 1.1 & 1.6 \\
\hline Luxembourg & 6.6 & 32 & 3.4 & 0.3 & 0.1 & 0.2 & 3.4 & 1.7 & 1.7 & 2.4 & 1.2 & 1.2 & 0.5 & 0.3 & 0.2 \\
\hline Hungary & 359.0 & 160.9 & 198.1 & 37.0 & 13.5 & 23.5 & 237.6 & 110.7 & 127.0 & 77.0 & 32.9 & 44.1 & 7.3 & 3.8 & 3.6 \\
\hline Malta & 12.6 & 5.6 & 7.0 & 2.5 & 1.1 & 1.3 & 69 & 30 & 39 & 3.1 & 1.4 & 1.7 & 0.1 & 0.0 & 0.0 \\
\hline Netherlands & 674.8 & 327.1 & 347.7 & 5.3 & 3.0 & 2.3 & 558.5 & 2727 & 285.7 & 97.3 & 44.5 & 52.9 & 13.6 & 6.9 & 6.8 \\
\hline Austria & 422.8 & 196.8 & 225.9 & 76.8 & 35.6 & 41.2 & 180.2 & 845 & 95.7 & 140.1 & 632 & 76.9 & 25.7 & 13.6 & 12.1 \\
\hline Poland & 1902.7 & 764.6 & 1138.1 & 10.9 & 20 & 8.9 & 1266.5 & 542.7 & 723.8 & 583.0 & 200.0 & 383.0 & 42.3 & 19.8 & 22.5 \\
\hline Portugal & 371.0 & 173.7 & 197.3 & - & - & - & 231.5 & 107.5 & 124.1 & 120.0 & 57.2 & 62.8 & 19.5 & 9.1 & 10.4 \\
\hline Romania & 618.2 & 284.9 & 333.2 & - & - & - & 409.6 & 199.1 & 210.5 & 187.2 & 75.0 & 1122 & 21.4 & 10.8 & 10.5 \\
\hline Slovenia & 97.7 & 41.5 & 56.2 & 13.4 & 7.6 & 58 & 549 & 230 & 31.9 & 258 & 9.2 & 16.6 & 3.6 & 1.7 & 1.9 \\
\hline Slovakia & 209.5 & 84.5 & 125.0 & 2.9 & 0.9 & 1.9 & 120.8 & 49.7 & 71.1 & 74.9 & 28.2 & 46.7 & 11.0 & 5.7 & 5.2 \\
\hline Finland & 309.0 & 143.1 & 165.9 & 0.1 & 0.1 & 0.0 & 228.3 & 109.1 & 119.2 & 60.1 & 24.1 & 36.0 & 20.6 & 9.9 & 10.7 \\
\hline Sweden & 436.6 & 176.0 & 260.6 & 26.0 & 13.1 & 129 & 2530 & 932 & 159.8 & 136.1 & 58.6 & 77.4 & 21.5 & 11.0 & 10.5 \\
\hline United Kingdom & 2386.2 & 1048.0 & 1338.2 & 326.8 & 124.5 & 2023 & 1526.7 & 686.7 & 840.0 & 423.6 & 178.9 & 244.7 & 109.1 & 58.0 & 51.1 \\
\hline Iceland & 19.1 & 7.2 & 11.9 & 0.5 & 0.2 & 0.2 & 13.8 & 5.4 & 8.4 & 44 & 1.4 & 30 & 0.5 & 0.2 & 0.3 \\
\hline Liechtenstein & 0.8 & 0.6 & 0.3 & - & - & - & 0.5 & 0.4 & 0.2 & 0.2 & 0.2 & 0.1 & 0.1 & 0.1 & 0.0 \\
\hline Norway & 255.4 & 105.2 & 150.2 & 9.8 & 7.3 & 25 & 181.9 & 69.8 & 112.2 & 56.3 & 24.5 & 31.8 & 7.4 & 3.6 & 3.8 \\
\hline Switzerland & 279.8 & 141.3 & 138.5 & 10.8 & 4.5 & 6.3 & 186.3 & 94.7 & 91.7 & 60.0 & 29.6 & 30.4 & 22.7 & 12.5 & 10.2 \\
\hline FYR of Macedonia & 60.7 & 27.6 & 33.1 & - & - & - & 56.9 & 25.9 & 31.0 & 3.6 & 1.6 & 2.0 & 0.2 & 0.1 & 0.1 \\
\hline Turkey & 4975.7 & 2706.9 & 2268.8 & 1527.7 & 827.8 & 699.9 & 3052.7 & 1657.5 & 1395.2 & 314.8 & 176.0 & 138.8 & 80.5 & 45.6 & 34.8 \\
\hline
\end{tabular}

PICBE | 334

Figure 1. Number of tertiary education students in the EU by level and sex, 2013 (thousands)

Source: http://ec.europa.eu/eurostat/statistics-explained/index.php/Tertiary_education_statistics.

Why does that happen? Obviously, one important reason is that Romania is one of the largest countries of the EU, with important resources including human capital. The various policies implemented in the last decade at the national level transformed the country which is now aligned, at least institutionally and at a surface level, to the requirements of the latest EU regulations. In terms of higher education this means that Romanian universities declare to have similar standards in terms of study programmes, quality assurance and transferable credits. However, the values of the academic community in Romania are still under a strong public debate which is not helped at all by the many changes the system is still going through (Miron, 2016; Seitz, Nicolae, 2014). One of the latest heated public discussions was the one around the criteria for evaluating professors, readers and doctoral coordinators that were to be changed again by the political decision makers. The reason was, as usual, the desire to have the new criteria more connected to the requirements of the international research community with little regard to the effect that such a change would have, in certain fields and/or disciplines, on a large part of the members of the academic community who would see their entire career rendered worthless.

The public debates of those new criteria in the field of economics and business pointed out that their adoption were almost similar with the termination of teaching in Romanian universities and of the Romanian research journals even if their language of publication was English. The debates also pointed out the long term, not completely perceivable effects on the entire Romanian society including the general attitude of young graduates who cannot be motivated and attracted to an academic career which continues to be unattractive because of the incomes it offers at entry level and unpalatable because of the high degree of stress and continuous demands on its members. 
However, the most important point that the communities of economic and business academics put forward was the lack of coherence and preparation of the process of desired change. This is an argument that is relevant for the present discussion because change management is clearly a function of the leaders of the education system and, mainly, of the Romanian government who should have a long term vision of the development of the country and of the blueprint to that development which clearly should be based on education. That this does not happen may be, among others, also a proof of the incapacity of those leaders to articulate a clear vision and, mainly, to be able to drive their constituencies to follow that vision and implement it. Such a vision and an understanding of the international values of higher education and of the local social needs would help Romanian universities to serve their stakeholders, the present Romanian society and our future generations of graduates.

\section{Developing leaders for competence and performance}

So how are the leaders of higher education trained or grown or developed in Romanian universities? It is not easy to find an answer to such a question due to the lack of transparency of the ways each university approaches this question. An investigation on the web sites of Romanian universities, a relatively time-consuming effort due to the unfriendly structuring of the information presented, shows that little is done in terms of formalized, transparent and open access training for university leaders and administrators in Romania or for those who are interested in following such a career path. As compared to, for example, UK, American or Australian universities in which you have a clear career path explained for those interested in academia.

For example, the Graduate School of Education from Harvard University offers for a tuition fee of $\$ 8,150$ a five day programme for "Newly Appointed First-Year Presidents". Through interactive sessions the programme promisses to address important issues for those who have become university presidents for the first time. The programme covers, among other topics: the contexts of leadership - that is the culture and traditions of a university; governance - the role of governing boards and the relation between the president and the board of trustees; presidential fundraising - which is probably the most important role for the president of an American university; building the administrative team - the role of the president as CEO and senior personnel officer; academic leadership - the position of the president as academic leader; strategic planning - the president's role in the design and implementation of strategic planning . That means to develop new patterns of thinking for students through improving curricula in higher education (Bratianu, 2007, 2009).

It is obvious that such programmes are not possible in the Romanian academic context for various reasons, including the costs of developing them and the culture of delivering them. Also, another important reason is that the European higher education systems, therefore the Romanian one as well, are still largely based on a collegial culture. It seems that most of the energies in the system of higher education are channeled towards winning the elections and not on how to be prepared for the job, with some notable exceptions in Romania under the form of European funded projects financed through the European Social Fund, such as the project Improving University Management (Nicolae, 2015, pp. 50-51). It seems, therefore that the training of the leaders in higher education has been left mostly to personal efforts, especially at the higher end of the system.

Nevertheless, in today's complex higher education system professional competence is an important component that cannot be left entirely to personal 
development needs. Formalized training in management, leadership, educational management, research management, organizational culture, strategic planning and time management skills are critical components for one's professional competence that would empower those academics working in administration to plan for their organization's performance in an open and transparent world.

\section{Methodology of research}

PICBE | 336

This paper is based on a doctoral research aiming to reveal the specificity of Romanian leadership issues in higher education. It is a conceptual paper using both qualitative and quantitative approaches to answer its research question which is: what is being done formally in the Romanian system of higher education to develop its leadership and, thus, ensure, its performance?

In order to answer that question it is important to underline that for the purpose of this paper the authors use the terms leadership/management/administration interchangeably to refer to the middle and top management of higher education institutions. We are aware of the discussions around this terminology and of the various perspectives that each term may open. However, this is not the focus of the present paper. It is also important to underline that trying to define university performance is also a daunting task that needs to be done separately considering the variety of higher education contexts and institutional approaches as pointed out by Platis (2016), Kallio \& Kuoppakangas, (2015), Nicolae (2014), Nicolescu, (2011) and many others.

\section{Discussion of findings}

The doctoral research of one of the authors of the present paper involved the administration of a questionnaire to a number of leaders in Romanian and international universities. From the 22 respondents interviewed in the research 14 had been Romanian and 8 international (Australia - Melbourne, France - Paris, Great Britain London, Russian Federation - St. Petersburg, USA - San Bernardino). From the point of view of the positions in the higher education system at the time of research the respondents had been: 6 Romanian rectors, 2 international rectors, 2 Romanian and 1 international vice rectors, 3 Romanian and 2 international deans, 6 respondents with various positions in the Romanian higher education system (a former Minister of Education of Romania, a president of the Academic Council of a Romanian university, directors of Doctoral Schools of Economics and Business, international experts in academic leadership).

Among the questions asked that we consider relevant for the present paper were the following: (1) Do you feel the need for specialized courses to develop leadership competences in higher education? (2) If not, why not? (3) If you do, what are the three crucial competences that should be covered in those courses?

The answers given by our respondents were complex, full of details and, consequently, difficult to analyze. Nevertheless, for our purpose here we would like to underline that question number one, referring to the need for specialized courses to develop leadership competences in higher education, was answered positively by the overwhelming majority of the respondents. More details on the research and a larger discussion of the issues only briefly presented here can be found in Nicolae $(2015$, pp 179 - 189).

The type of competences considered necessary to be developed or improved in training revealed in the answers of the Romanian respondents ranged from disciplines to be studied such as educational management, human resource management, strategic 
management and leadership in higher education, research management, organizational culture, strategic planning to competences or abilities such as efficiency, adaptability, flexibility, holistic thinking and, expressed under various forms, time management skills. The respondents' emphasis on disciplines is a cultural characteristic for Romania where learning is still perceived to happen mostly if one can prove that one has the official record for attending the respective training, not if one can demonstrate the competence irrespective of how that was acquired. However, we can conclude that if in Romania new leaders are trained in a diffuse manner, across departments and disciplines, with little visible mentoring, or are left to do their own professional development, which has been mostly the case so far, in all the international universities that were part of the above mentioned research (with the exception of Russia) leadership training is well established and done either by the human resource departments or by specialized, dedicated departments. Or, as we mentioned before, leadership training is available, freely and openly, for an adequate fee, to all those interested in their personal and professional development. Who actually pays those high fees, individuals or institutions, is another discussion.

The challenges societies and, consequently, higher education face all over the world require a high degree of human character and professional competence from the leaders of universities and other higher education institutions to lead their organizations through these turbulent times. Constant and changing demands of multiple and often contradictory stakeholders, continually increasing regulations, increasing and tough competition to attract students, new technologies and methods for delivering education, diminishing funding and a growingly skeptical public are challenges that all universities have to face. Those which invest in the development of their leaders or managers or administrators will clearly be in a better position to face those challenges.

\section{Conclusions}

Higher education continues to be acknowledged as one of the important drivers of development in a knowledge intensive society and economy. Romania, now a decade-old member state of the European Union, needs to continue and improve its efforts to meaningfully contribute to the EU and to the complex process of the transformation of Europe even if the European Union itself is unsure at the moment what that means. Romania could be successful if it finalizes its never-ending reforms of its higher education system by realistically rethinking its priorities for education and research, by making the long declared and never implemented decisions to correctly fund education and research, by integrating itself in the main flow of thinking and good practices of international leadership today, including formalized training and development, and by giving itself and its people the time to internalize values and good practices.

Therefore, at present, the answers to the questions raised in the title of this paper are, sadly, that individuals continue to be requested to do most of their own development, with still little transparent institutional support, while our organizations appropriate those efforts, quantify and report them as their own without properly having contributed to them. In Romania both organizations and individuals need to understand the need to offer opportunities for professional training and the need to invest in personal development.

\section{References}

Bratianu, C. (2007). Thinking patterns and knowledge dynamics. In D. Remenyi (Ed.). 
Proceedings of the $8^{\text {th }}$ European Conference on Knowledge Management (pp.152156), Consorci Escola Industrial, Barcelona, Spain, 6-7 September 2007. Reading: Academic Conferences and Publishing International.

Bratianu, C. (2009). The frontier of linearity in the intellectual capital metaphor. In C. Stam (Ed.). Proceedings of the European Conference on Intellectual Capital (pp. 97103), Inholland University of Applied Sciences, Haarlem, The Netherlands, 2829 April 2009.

Caplan, B., (2012), The Case Against Education, https://www.youtube.com/watch?v=bpk_u_VmPD4.

Hartford, T., (2016). Are universities worth it? Financial Times, 24 August 2016, www.ft.com/content/f1cae73c-6982-11e6-ae5b-a7cc5dd5a28c.

Kallio, K.M., Kuoppakangas, P., (2015). Key dilemmas of performance measurement in the context of Finnish higher education - an empirical case study, International Research Society for Public Management Conference 2015, http://irspm2015.com/index.php/irspm/IRSPM2015/paper/view/1047/357.

Miron, D., (2016), The most pressing challenges for Romanian Higher Education System in line with the Bologna Process values, Challenges, performances and tendencies in Organization Management (Editors: O. Nicolescu, L. Lloyd-Reason), http://www.worldscientific.com/worldscibooks/10.1142/9494.

Nicolae, M., (2015), Educație și leadership. Realități și experiențe românești, Editura ASE, Bucuresti.

Nicolae, M., (2016), Study Programmes in English in Non-Anglophone Countries. Looking at Impacts and Challenges from a Romanian Perspective, Challenges, Performances and Tendencies in Organisation Management (Editors: O. Nicolescu, L. Lloyd-Reason), http://www.worldscientific.com/worldscibooks/10.1142/9494.

Nicolescu, L. (2009). Integrating Teaching and Research. An Institutional Case in Romania. Proceedings Business Excellence vol 2., ISBN 978-973-1747-12-5, pp. 5457.

Nicolescu, L. (2010). Governance in Higher Education: theories and practices. Metalurgia Internaţional, vol XV, Special Issue no. 1, pp. 201-205.

Nicolescu, L. (2011). Student experience in Romanian higher education - a comparative institutional approach. Transformations in Business \& Economics, vol. 10, no. 2B (23B).

Platis, M., (2016), Role of University Rankings in the Context of Lack of Resources: National and Institutional Challenges, in Kevin Downing, Fraide A. Ganotice, Jr. (eds), World University Rankings and the Future of Higher Education, (pages 186208), IGI Global,http://www.igi-global.com/book/world-university-rankingsfuture-higher $/ 150147$.

Seitz, V., Nicolae, M., (2014). The Role of Academic Values in Higher Education Convergence in Romania: A New Approach, Handbook of Research Trends in European Higher Education Convergence, IGI Global, http://www.igiglobal.com/book/handbook-research-trends-european-higher/97340. 